1 Aggressive behavior of the male parent predicts brood sex ratio in a songbird

2

3 Eszter Szász ${ }^{1}$, László Zsolt Garamszegi ${ }^{2}$, Gergely Hegyi ${ }^{1}$, Eszter Szöllősi ${ }^{1}$, Gábor Markó ${ }^{13}$, 4 János Török ${ }^{1}$ and Balázs Rosivall ${ }^{1}$

5

$6{ }^{1}$ Behavioural Ecology Group, Department of Systematic Zoology and Ecology, Eötvös 7 Loránd University, Pázmány Péter sétány 1/c, H-1117, Budapest, Hungary

$8{ }^{2}$ Department of Evolutionary Ecology, Estación Biológica de Doñana-CSIC, c/Americo $9 \quad$ Vespucio, s/n, 41092, Seville, Spain

$10{ }^{3}$ Department of Plant Pathology, Corvinus University of Budapest, Ménesi út 44, H-1118, 11 Budapest, Hungary

12

13 Correspondence: Eszter Szász; E-mail address: iciperezvon@gmail.com; Telephone: +36-13722500 ext. 8755; Fax: +36-1-3812194 


\section{Aggressive behavior of the male parent predicts brood sex ratio in a songbird}

Abstract Brood sex ratio is often affected by parental or environmental quality, presumably in an adaptive manner that is the sex that confers higher fitness benefits to the mother is overproduced. So far, studies on the role of parental quality have focused on parental morphology and attractiveness. However, another aspect, the partner's behavioral characteristics, may also be expected to play a role in brood sex ratio adjustment. To test this hypothesis, we investigated whether the proportion of sons in the brood is predicted by the level of territorial aggression displayed by the father, in the collared flycatcher (Ficedula albicollis). The proportion of sons in the brood was higher in early broods and increased with paternal tarsus length. When controlling for breeding date and body size, we found a higher proportion of sons in the brood of less aggressive fathers. Male nestlings are more sensitive to the rearing environment, and the behavior of courting males may often be used by females to assess their future parental activity. Therefore, adjusting brood sex ratio to the level of male aggression could be adaptive. Our results indicate that the behavior of the partner could indeed be a significant determinant in brood sex ratio adjustment, which should not be overlooked in future studies.

Keywords Attack latency; Collared flycatcher; Laying date; Male quality; Personality; Sex allocation 


\section{Introduction}

The brood sex ratio that provides maximal fitness benefit is expected to vary between females when their individual physical, social and ecological conditions differently influence the fate of male and female offspring. In such a case, selection should favor the ability of mothers to adjust the sex ratio of their brood. According to the Trivers-Willard-hypothesis (Trivers and Willard 1973), mothers in above-average body condition should produce male-biased broods, whereas mothers in below-average body condition should produce female-biased broods, whenever male reproductive success is more variable and hence more dependent on maternal investment than female reproductive success. Indeed, such a pattern has been found in certain bird species, for example in the tree swallow (Tachycineta bicolor) (Whittingham and Dunn 2000) and the house wren (Troglodytes aedon) (Whittingham et al. 2002). Moreover, brood sex ratio has been shown to vary as a function of partner quality (e.g. ornament size in Ellegren et al. 1996; body size in Kölliker et al. 1999; strophe bout length in Dreiss et al. 2006), breeding date (Daan et al. 1996) and territory quality (Appleby et al. 1997), factors that, similarly to maternal condition, can affect future reproductive success of the offspring in a sex-specific manner. Other hypotheses focus on the survival prospect of the offspring or the mother because of differences in early sensitivity and energy demand between male and female offspring (Cordero et al. 2000; Martins 2004; Addison et al. 2008; Rosivall et al. 2010). On the one hand, mothers breeding in poor body condition or an unfavorable environment might overproduce the sex that is less susceptible to nutrient shortage, because it has a greater chance to survive under such a condition (Kilner 1998; Nager et al. 1999). On the other hand, mothers breeding in poor body condition or an unfavorable environment might overproduce the sex that is less costly to rear, thereby facilitating their own survival and thus future breeding probability (Gomendio et al. 1990). Notably, the less sensitive and the less expensive sex may often be the same, making these hypotheses difficult to distinguish. 
To date, parental morphological traits (i.e. body condition and body size), male secondary sexual characters (i.e. plumage and song features) and ecological factors (usually some indicator of food availability) have been considered as cues for brood sex ratio adjustment, while behavioral traits of the partner have been ignored. Recent results on behavioral traits, however, suggest that these could be as important determinants in brood sex ratio adjustment as morphological traits. First, behavioral traits show consistent variation across time and contexts even among individuals of the same sex and age (Réale et al. 2007; Bell et al. 2009). Second, selection experiments have demonstrated that this variation has a partly genetic background (van Oers et al. 2005; Fidler et al. 2007). Third, behavioral traits may have different impact on male and female fitness (Dingemanse et al. 2004; Dunn et al. 2011). Therefore, we can expect that the behavior of parents influences the fate of the offspring in a sex-specific way via either genetic inheritance or parental care.

To test the hypothesis that the behavior of the partner plays a role in brood sex ratio adjustment, we performed an exploratory study on the relationship between male aggression and offspring sex ratio in a wild population of a small passerine, the collared flycatcher (Ficedula albicollis). Aggression is one of the most important and most widely studied behavioral traits, owing to its close link to fitness. In collared flycatcher males, aggression is repeatable in a single context and correlated across multiple contexts, indicating individual personalities (Garamszegi et al. 2006; Garamszegi et al. 2012). Moreover, aggression may give comprehensive information about the behavior of the males because functionally different behavioral traits (e.g. aggression and exploration) correlate with each other within an individual and form a behavioral syndrome (Garamszegi et al. 2009).

Male aggression is likely to be involved in brood sex ratio adjustment because females can assess it before egg laying in at least two different ways. First, more aggressive males may court more intensively, because intra- and inter-sexual behaviors are governed by a 
shared physiological background (Eising et al. 2006). Additionally, more aggressive males may also act more violently when courting, for example force females to copulate or cause physical injury to them (Ophir and Galef 2003). Second, females can gain information about male aggression directly by eavesdropping on male-male interactions before pairing (Naguib and Todd 1997; Otter et al. 1999).

Male aggression may have sex-specific impact on offspring fitness via genetic inheritance because aggression has a moderate heritability (e.g. in the house mouse (Mus musculus domesticus), $h^{2}=0.30$ in van Oortmerssen and Bakker 1981 and $h^{2}=0.40$ in Gammie et al. 2006; in the western bluebird (Sialia mexicana), $h^{2}=0.45$ in Duckworth and Badyaev $\underline{2007)}$ and male reproductive success may be more dependent on aggression than female reproductive success. In the collared flycatcher, aggression is necessary for males to successfully compete with each other for breeding territories and thus attract mates. Male aggression may have sex-specific impact on offspring fitness also via parental care, because mating and parental behaviors are often conflicting (Ketterson et al. 1992; Stoehr and Hill 2000; Peters 2002) and the future prospects of male and female offspring may be differently dependent on parental investment. In our study population, male offspring have greater growth potential but are also more sensitive, so under good conditions male, while under poor conditions female offspring perform better (Rosivall et al. 2010; Hegyi et al. 2011). Altogether, we predicted one of two scenarios for male aggression related brood sex ratio adjustment. First, if aggression is particularly advantageous for males in terms of reproductive success, mates of more aggressive males might overproduce sons, while mates of less aggressive males might overproduce daughters. Second, if aggression in males is negatively related to their contribution to parental care, mates of more aggressive males might overproduce daughters, while mates of less aggressive males might overproduce sons. 
Data collection

112 The study was conducted in a nest box breeding population of the collared flycatcher, in the Pilis Mountains, Hungary $\left(47^{\circ} 43^{\prime} \mathrm{N}, 19^{\circ} 01^{\prime} \mathrm{E}\right)$. The collared flycatcher is an insectivorous, migratory, secondary hole-breeding, primarily monogamous passerine with normally one clutch per breeding season. The most common clutch size is 6-7 eggs. Only females incubate the eggs, but both parents care for the nestlings. Males arrive at the breeding site before females and immediately start to acquire and defend nest boxes. They then begin to attract arriving females by singing, displaying and presenting their nest box (Cramp and Perrins 1993).

We measured male aggression at this courtship stage (in the middle of April) by presenting territory owner males with a live decoy male to stimulate male-male aggression. Stimulus males were placed in a small wire cage $(20 \times 15 \times 15 \mathrm{~cm})$, so the focal males were not able to injure them. Multiple stimulus males were randomly used across tests and were unfamiliar with the owner males. Tests were made during the most active period (between 5:00 a.m. and 10:00 a.m.) and under good weather conditions. To quantify aggression, we recorded the latency of the first attack of the focal male, which was the time elapsed between the detection of and the first attack toward the intruder male. The detection was defined as the appearance of the owner male on its territory, and the first attack as the first event when the owner male touched the cage of the intruder male (usually with clear intention to fight). The latency of the first attack is a reliable measure of aggression, since it is repeatable within males ( $R=0.383$ in Garamszegi et al. 2012) and correlates with other variables describing territorial aggression (e.g. frequency and average duration of attacks, see Garamszegi et al. 2006). The tests lasted five minutes (after the appearance of the focal male), because according to our previous observations, males that did not respond to the stimulus in terms of 
aggressive approach within five minutes did not respond at all. As previously, non-responder focal males were given a score of $301 \mathrm{sec}$ for attack latency (Garamszegi et al. 2006).

After the behavioral test, focal males were trapped for ringing and morphological measurements. We measured the size of two white plumage characters of the males, the forehead patch and the wing patch, which are important in social interactions (Garamszegi et al. 2006; Hegyi et al. 2010), and tarsus length as an indicator of structural body size. Based on the color of the remiges, males were categorized as yearlings or adults (Svensson 1992). Following the measurements, males were released and their breeding attempt was monitored to assess the date of the first egg and the total number of eggs laid by their mates. To determine brood sex ratio, we collected small blood samples from the nestlings (at the age of 9-13 days) and embryonic tissue samples from the unhatched fertile eggs. The protocol of the molecular sex determination had been validated on adults of known sex, for details see Rosivall et al. (2004). In total, out of the 171 eggs laid in 27 broods, 150 were sexed from nestling blood sample, 5 from embryonic tissue sample and 2 were unfertile. We had no information about 4 eggs and 10 nestlings that had disappeared before sampling. Therefore, we had complete information on the sex ratio for 17 broods, while incomplete information was available for an additional 10 broods that were also used in the analysis.

\section{Data analysis}

The analysis included 27 broods (from 27 different pairs) from three years (6 broods from 2005, 14 broods from 2007 and 7 broods from 2010). We analyzed the data by fitting a generalized linear mixed model with binomial error distribution, logit link function and Satterthwaite's approximation of degrees of freedom. We used the number of male offspring in the brood as the dependent variable and the total number of sexed offspring as the binomial denominator, so brood sex ratio refers to the proportion of male offspring in the brood. The 
fixed variables entered in the initial model were the latency of the first attack (logarithmically transformed), the wing patch size (standardized across age categories; see Török et al. 2003), the tarsus length and the binary age of the male, the laying date of the first egg (as a deviation from the median clutch initiation date of the given year) and year. The explanatory variables were statistically independent of each other (all $p>0.1$ ). To account for the possible confounding effect of the stimulus male (Garamszegi et al. 2006), the identity of the stimulus male was also included in our model as a random factor. Non-significant variables were removed one by one using a backward stepwise selection procedure. We present $F$-statistic values for each explanatory variable and effect size (Pearson's $r$ ) with 95\% confidence intervals calculated from $F$-values according to Rosenthal (1994). The analysis was performed in SAS version 9.1 using the GLIMMIX macro (SAS Institute Inc., USA, 1990).

Neither embryo nor nestling mortality is sex-biased in our study population (our unpublished results). Moreover, the proportion of sampled progenies in the brood was independent of all the explanatory variables considered in the analyses of brood sex ratios (all $p>0.1$ ). Therefore, the analyzed brood sex ratios can be regarded as primary brood sex ratios (i.e. sex ratios at egg laying).

\section{Results}

We found a significant positive relationship between the sex ratio of the brood and the latency of the first attack of the male (Fig. 1, Table 1). Given that there is an inverse relationship between attack latency and aggression (i.e. the more aggressive the male, the faster he attacks), the direction of the relationship indicates that the proportion of sons in the brood decreased with the aggression of the father. The brood sex ratio was significantly positively related to the tarsus length of the male (Fig. 2, Table 1) and significantly declined with the progress of the breeding season (Table 1). There was a non-significant tendency for an 
increase in brood sex ratio with male wing patch size, but brood sex ratio was not affected by male forehead patch size, male age and year (Table 1).

\section{Discussion}

Manipulating the sex ratio of the brood may be adaptive, whenever the fitness of male and female offspring is differentially influenced by parental attributes or environmental factors. The behavior of parents is likely to influence the fitness of male and female offspring differently for at least two reasons. First, behavioral traits may be at least partially heritable (van Oers et al. 2005) and the sexes may have different fitness optima for shared behavioral traits (Dingemanse et al. 2004; Dunn et al. 2011). Second, there may be an association between parental behavior and the quality of care (e.g. Both et al. 2005; Duckworth 2006) and the sexes are known to differ in their early susceptibility to rearing conditions in many species (Råberg et al. 2005).

Our study is the first that regards a behavioral trait of the partner as a possible predictor of brood sex ratio in animals. We demonstrated in a wild bird population that aggressive behavior of the male during the period of mate attraction is related to the proportion of sons in his subsequent brood. The less aggression was displayed by the male in a simulated territorial conflict, the more sons were produced by his mate.

This relationship can be adaptive, if more aggressive males contribute less to parental care and female offspring are less sensitive to rearing conditions. Actually, in the same collared flycatcher population, male nestlings grew faster in experimentally reduced broods, but grew slower in experimentally enlarged broods than female nestlings (Rosivall et al. 2010). Furthermore, food supply, estimated by caterpillar abundance, had a stronger effect on body mass growth in male than in female nestlings (Hegyi et al. 2011). This suggests that males have a greater growth potential but are more sensitive, thus profiting more from 
favorable rearing conditions and suffering more from unfavorable rearing conditions than

females. Although we have no direct data linking male aggression to parental care, assuming such a link is reasonable in birds. In males, testosterone has a conflicting effect on mating and parental effort, as it facilitates sexual and aggressive behaviors, while suppresses parental behaviors (Wingfield et al. 1987). Furthermore, the magnitude and duration of testosterone elevation during the breeding season has been reported to vary among males and suggested to be the basis for some of the individual variation in allocation to mating versus parental effort (reviewed by Kempenaers et al. 2008). In the pied flycatcher (Ficedula hypoleuca), the sibling species of our study species, testosterone treated males prolonged their singing activity and acquired more territories, while, at a later phase, they performed negligible feeding activity or abandoned their brood (Silverin 1980). In the western bluebird, males that were more aggressive towards conspecific males in a simulated territorial conflict fed their nestlings at a lower rate (Duckworth 2006). Additionally, there is indication in both pied and collared flycatchers, that reduced paternal contribution to nestling feeding reduces the fledging success of the brood (Silverin 1980; Garamszegi et al. 2004). Consequently, if a trade-off between allocation to male aggression and nestling care exists in our collared flycatcher population, mates of more aggressive males may maximize their fitness benefit by producing disproportionately more daughters, because these nestlings may suffer less from the reduced paternal provision and thus fledge with higher success. Mothers receiving less help from their mate can also enhance their own survival through such an adjustment because female nestlings may impose less cost on them due to their smaller energy demand. Producing disproportionately more sons when mated to a less aggressive male may be beneficial for mothers because male nestlings may perform better in case of intensive male assistance in parental care. In addition, the fitness benefit through good-provisioned sons may exceed the fitness benefit through good-provisioned daughters in our population, due to a greater 
reproductive potential for males created by polygynous mating and extra-pair fertilizations (Garamszegi et al. 2004; Rosivall et al. 2009).

The results contradict our alternative scenario of a positive relationship between brood sex ratio and paternal aggression, which would require that the heritable variation in aggression is linked to reproductive success in a sex-dependent way. Perhaps a sex-difference in developmental sensitivity or early energy requirement provokes stronger selection for brood sex ratio adjustment to paternal aggression in the opposite direction because it not only influences the number of offspring produced, but also the chance whether or not an individual reaches reproductive age. Furthermore, the benefits of inherited aggression may not be limited to males, as female collared flycatchers also perform aggression towards same-sex intruders, which may help them to prevent polygynous mating (Garamszegi et al. 2004; Hegyi et al. 2008).

As in a previous study (Rosivall et al. 2004), the clutch initiation date had a significant effect on the brood sex ratio. However, because the territorial intrusion tests were conducted in a relatively short period due to logistic constraints, the clutch initiation dates in the present study do not characterize the entire population. Therefore, this result has to be handled carefully. Nonetheless, the negative relationship between brood sex ratio and laying date may partially be driven by selective pressures similar to those suggested for the negative relationship between brood sex ratio and male aggression. Namely, if early in the season food is more abundant, mothers might maximize their fitness benefit by producing an excess of sons, which may perform better than daughters under favorable conditions. As food becomes scarcer with the progress of the season and mothers also face energetic constraints due to the upcoming molt and migration, they might maximize their fitness benefit by producing an excess of daughters, the sex that performs better under unfavorable conditions and requires less expenditure to rear. For a better understanding of the seasonal brood sex ratio pattern in 
our study population, a more detailed analysis of the temporal distribution of food is needed, as food abundance and brood sex ratio may not simply decrease during the breeding season but may show more complex patterns. For example, our previous study focusing on a single year when birds arrived at the breeding site in two distinct waves, found an increase in brood sex ratio for the whole season (Rosivall et al. 2004), no shift for the first wave separately and a decrease for the second wave separately (our unpublished results). Still, timing of breeding seems to be an important factor in sex ratio adjustment of collared flycatcher females, at least in the central area of the species, as in a Czech population, Bowers et al. (2013) also found indication for a seasonal decrease in brood sex ratio.

Contrary to the results in a Swedish population (Ellegren et al. 1996) and in line with our previous report (Rosivall et al. 2004), we did not find significant relationship between male forehead patch size and brood sex ratio. There was, however, a non-significant tendency for a positive relationship between the wing patch size of the male and the proportion of sons in the brood. Such relationship was not found previously (Rosivall et al. 2004). It is plausible that the benefit of sex ratio adjustment in relation to male attractiveness is context-dependent, because other selective pressures, such as year quality, that act on offspring survival rather than future reproductive success may override its importance (see e.g. Addison et al. 2008). The between-population difference in the role of male ornaments can be explained by the different information content of these traits. In our study population, wing patch size is condition-dependent (Török et al. 2003) and has both intra- and intersexual function (Garamszegi et al. 2006; Hegyi et al. 2010), while in the Swedish population, forehead patch size serves as a condition-dependent quality indicator (Gustafsson et al. 1995). The results in the Czech population were similar to ours, that is brood sex ratio was positively related to male wing patch size and unrelated to male forehead patch size (Bowers et al. 2013). According to some recent theoretical work (Booksmythe et al. 2013), the difference among 
populations in sex ratio adjustment in relation to male ornamentation may reflect population difference in the coupled evolution of male ornament expression level, female preference and facultative sex allocation.

We found that male tarsus length was a significant predictor of brood sex ratio. Note that the effect of paternal body size on brood sex ratio was independent of the effect of paternal aggression, since the two male characteristics were unrelated. Though, in our previous study, the provisioning activity of parents was not linked to their own or their mate's tarsus length (Kiss et al. 2013), if larger body size is associated with access to superior territories, as in the Swedish population (Gustafsson 1988), the positive relationship between brood sex ratio and paternal tarsus length could also be explained by the sex-specific response of nestlings to rearing conditions (Rosivall et al. 2010; Hegyi et al. 2011). Unfortunately, in the Czech population, male tarsus length was not considered (Bowers et al. 2013), however, interestingly, in the Swedish population, male tarsus length did not affect brood sex ratio (Ellegren et al. 1996).

To conclude, our results provide evidence for the so far untested hypothesis that, considering their potential sex-specific effects on offspring fitness, behavioral traits of the partner can be involved in brood sex ratio adjustment. We believe that extending the analyses on brood sex ratio adjustment to the behavior of the partner may help explain some apparent discrepancies in the literature. For example, regarding the general negative link between mating and parental effort mediated by a shared hormonal background, selection for offspring sex ratio adjustment to the level of male care can account for the lack of an expected relationship between offspring sex ratio and male sexual ornaments, that is, attractiveness. Further studies in multiple systems are clearly needed to test the generality of the phenomenon we described here. 
310 We thank Rita Főző, Márton Herényi, Dorottya Kiss, Miklós Laczi, Gergely Nagy and Sándor

311 Zsebök for their help in the field and the lab and two anonymous referees for their valuable

312 comments on the manuscript. We are also very grateful to the Pilis Park Forestry for its

313 support.

314

315 Funding

316 The study was supported by grants from the Hungarian Scientific Research Found (grant no.

317 F68295, PD75481, K75618, K101611), the Social Renewal Operational Programme of the

318 Hungarian Government (TÁMOP 4.2.1./B-09/1-KMR-2010-0005 and 4.2.2./B-10/1-2010-

319 0023), the Hungarian State PhD Scholarship to E. Szász, the Erdök a Közjóért Alapítvány,

320 and the "Plan Nacional" program of the Spanish Government (ref. no. CGL2009-10652). 


\section{References}

Addison B, Kitaysky AS, Hipfner JM (2008) Sex allocation in a monomorphic seabird with a single-egg clutch: test of the environment, mate quality, and female condition hypotheses. Behav Ecol Sociobiol 63:135-141

Appleby BM, Petty SJ, Blakey JK, Rainey P, Macdonald DW (1997) Does variation of sex ratio enhance reproductive success of offspring in tawny owls (Strix aluco)? Proc R Soc Lond B 264:1111-1116

Bell AM, Hankison SJ, Laskowski KL (2009) The repeatability of behaviour: a meta-analysis. Anim Behav 77:771-783

Booksmythe I, Schwanz LE, Kokko H (2013) The complex interplay of sex allocation and sexual selection. Evolution 67:673-678

Both C, Dingemanse NJ, Drent PJ, Tinbergen JM (2005) Pairs of extreme avian personalities have highest reproductive success. J Anim Ecol 74:667-674

Bowers EK, Munclinger P, Bureš S, Kučerová L, Nádvorník P, Krist M (2013) Crossfostering eggs reveals that female collared flycatchers adjust clutch sex ratios according to parental ability to invest in offspring. Mol Ecol 22:215-228

Cordero PJ, Griffith SC, Aparicio JM, Parkin DT (2000) Sexual dimorphism in house sparrow eggs. Behav Ecol Sociobiol 48:353-357

Cramp S, Perrins CM (1993) The birds of the Western Palearctic, VII. Flycatchers to shrikes. Oxford University Press, Oxford

Daan S, Dijkstra C, Weissing FJ (1996) An evolutionary explanation for seasonal trends in avian sex ratios. Behav Ecol 7:426-430

Dingemanse NJ, Both C, Drent PJ, Tinbergen JM (2004) Fitness consequences of avian personalities in a fluctuating environment. Proc R Soc Lond B 271:847-852 
Dreiss A, RichardM, Moyen F, White J, Møller AP, Danchin E (2006) Sex ratio and male sexual characters in a population of blue tits, Parus caeruleus. Behav Ecol 17:13-19

Duckworth RA (2006) Behavioral correlations across breeding contexts provide a mechanism for a cost of aggression. Behav Ecol 17:1011-1019

Duckworth RA, Badyaev AV (2007) Coupling of dispersal and aggression facilitates the rapid range expansion of a passerine bird. Proc Natl Acad Sci USA 104:15017-15022

Dunn JC, Cole EF, Quinn JL (2011) Personality and parasites: sex-dependent associations between avian malaria infection and multiple behavioural traits. Behav Ecol Sociobiol $65: 1459-1471$

Eising CM, Müller W, Groothuis TGG (2006) Avian mothers create different phenotypes by hormone deposition in their eggs. Biol Lett 2:20-22

Ellegren H, Gustafsson L, Sheldon BC (1996) Sex ratio adjustment in relation to paternal attractiveness in a wild bird population. Proc Natl Acad Sci USA 93:11723-11728

Fidler AE, van Oers K, Drent PJ, Kuhn S, Mueller JC, Kempenaers B (2007) Drd4 gene polymorphisms are associated with personality variation in a passerine bird. Proc. R Soc Lond B 274:1685-1691

Gammie SC, Garland T, Stevenson SA (2006) Artificial selection for increased maternal defense behavior in mice. Behav Genet 36:713-722

Garamszegi LZ, Eens M, Török J (2009) Behavioural syndromes and trappability in freeliving collared flycatchers, Ficedula albicollis. Anim Behav 77:803-812

Garamszegi LZ, Rosivall B, Hegyi G, Szöllősi E, Török J, Eens M (2006) Determinants of male territorial behavior in a Hungarian collared flycatcher population: plumage traits of residents and challengers. Behav Ecol Sociobiol 60:663-671 
Garamszegi LZ, Rosivall B, Rettenbacher S, Markó G, Zsebők S, Szöllősi E, Eens M, Potti J, Török J (2012) Corticosterone, avoidance of novelty, risk-taking and aggression in a wild bird: no evidence for pleiotropic effects. Ethology 118:621-635

Garamszegi LZ, Török J, Michl G, Møller AP (2004) Female survival, lifetime reproductive success and mating status in a passerine bird. Oecologia 138:48-56

Gomendio M, Clutton-Brock TH, Albon SD, Guinness FE, Simpson MJ (1990) Mammalian sex ratios and variation in costs of rearing sons and daughters. Nature 343:261-263

Gustafsson L (1988) Inter- and intraspecific competition for nest holes in a population of the collared flycatcher Ficedula albicollis. Ibis 130:11-16

Gustafsson L, Qvarnström A, Sheldon BC (1995) Trade-offs between life-history traits and a secondary sexual character in male collared flycatchers. Nature 375:311-313

Hegyi G, Garamszegi LZ, Eens M, Török J (2008) Female ornamentation and territorial conflicts in collared flycatchers (Ficedula albicollis). Naturwissenschaften 95:993-996

Hegyi G, Rosivall B, Szöllősi E, Eens M, Török J (2011) Context-dependent effects of nestling growth trajectories on recruitment probability in the collared flycatcher. Behav Ecol Sociobiol 8:1647-1658

Hegyi G, Szöllősi E, Jenni-Eiermann S, Török J, Eens M, Garamszegi LZ (2010) Nutritional correlates and mate acquisition role of multiple sexual traits in male collared flycatchers. Naturwissenschaften 97:567-576

Kempenaers B, Peres A, Foerster K (2008) Sources of individual variation in plasma testosterone levels. Phil Trans R Soc B 363:1711-1723

Ketterson ED, Nolan V, Wolf L, Ziegenfus C (1992) Testosterone and avian life histories: effects of experimentally elevated testosterone on behavior and correlates of fitness in the dark-eyed junco (Junco hyemalis). Am Nat 140:980-999 
Kilner R (1998) Primary and secondary sex ratio manipulation by zebra finches. Anim Behav $56: 155-164$

Kiss D, Hegyi G, Török J, Rosivall B (2013) The relationship between maternal ornamentation and feeding rate is explained by intrinsic nestling quality. Behav Ecol Sociobiol 67:185-192

Kölliker M, Heeb P, Werner I, Mateman AC, Lessells CM, Richner H (1999) Offspring sex ratio is related to male body size in the great tit (Parus major). Behav Ecol 10:68-72

Martins TLF (2004) Sex-specific growth rates in zebra finch nestlings: a possible mechanism for sex ratio manipulation. Behav Ecol 15:174-180

Nager RG, Monaghan P, Griffiths R, Houston DC, Dawson R (1999) Experimental demonstration that offspring sex ratio varies with maternal condition. Proc Natl Acad Sci USA 96:570-573

Naguib M, Todt D (1997) Effects of dyadic interactions on other conspecific receivers in nightingales. Anim Behav 54:1535-1543

Ophir AG, Galef BG (2003) Female Japanese quail that 'eavesdrop' on fighting males prefer losers to winners. Anim Behav 66:399-407

Otter K, McGregor PK, Terry AMR, Burford FRL, Peake TM, Dabelsteen T (1999) Do female great tits (Parus major) assess males by eavesdropping? A field study using interactive song playback. Proc R Soc Lond B 266:1305-1309

Peters A (2002) Testosterone and the trade-off between mating and paternal effort in extrapair-mating superb fairy-wrens. Anim Behav 64:103-112

Råberg L, Stjernman M, Nilsson JÅ (2005) Sex and environmental sensitivity in blue tit nestlings. Oecologia 145:496-503

Réale D, Reader SM, Sol D, McDougall PT, Dingemanse NJ (2007) Integrating animal temperament within ecology and evolution. Biol Rev 82:291-318 
Rosenthal R (1994) Parametric measures of effects size. In: Cooper H, Hedges LV (eds) The handbook of research synthesis. Russell Sage Foundation, New York, pp 231-244

Rosivall B, Szöllősi E, Hasselquist D, Török J (2009) Effects of extra-pair paternity and sex on nestling growth and condition in the collared flycatcher, Ficedula albicollis. Anim Behav 77:611-617

Rosivall B, Szöllősi E, Hasselquist D, Török J (2010) Males are sensitive - sex-dependent effect of rearing conditions on nestling growth. Behav Ecol Sociobiol 10:1555-1562

Rosivall B, Török J, Hasselquist D, Bensch S (2004) Brood sex ratio manipulation in collared flycatchers (Ficedula albicollis): results differ between populations. Behav Ecol Sociobiol 56:346-351

Silverin B (1980) Effects of long-acting testosterone treatment on free-living pied flycatchers, Ficedula hypoleuca, during the breeding season. Anim Behav 28:906-912

Stoehr AM, Hill GE (2000) Testosterone and the allocation of reproductive effort in male house finches (Carpodacus mexicanus). Behav Ecol Sociobiol 48:407-411

Svensson L (1992) Identification guide to European passerines. British Trust for Ornithology, Stockholm

Török J, Hegyi G, Garamszegi LZ (2003) Depigmented wing patch size is a conditiondependent indicator of viability in male collared flycatchers. Behav Ecol 14:382-388

Trivers RL, Willard DE (1973) Natural selection of parental ability to vary the sex ratio of offspring. Science 179:90-92

van Oers K, de Jong G, van Noordwijk AJ, Kempenaers B, Drent PJ (2005) Contribution of genetics to the study of animal personalities: a review of case studies. Behaviour $142: 1191-1212$

van Oortmerssen GA, Bakker CM (1981) Artificial selection for short and long attack latencies in wild Mus musculus domesticus. Behav Genet 11:115-126 
442 Whittingham LA, Dunn PO (2000) Offspring sex ratios in tree swallows: females in better condition produce more sons. Mol Ecol 9:1123-1129

444 Whittingham LA, Valkenaar SM, Poirier NE, Dunn PO (2002) Maternal condition and 445 nestling sex ratio in house wrens. The Auk 119:125-131

446 Wingfield JC, Ball GF, Dufty AM, Hegner RE, Ramenofsky M (1987) Testosterone and 447 aggression in birds. Am Sci 75:602-608 
$448 \quad$ Figure captions

$449 \quad$ Fig. 1

450 Brood sex ratio in relation to paternal attack latency in the collared flycatcher. Given that 451 there is an inverse relationship between attack latency and aggression (i.e. the more 452 aggressive the male, the faster he attacks), the direction of the relationship indicates that the 453 proportion of sons in the brood decreased with the aggression of the father

454

455 Fig. 2

456 Brood sex ratio in relation to paternal tarsus length in the collared flycatcher 
458 Brood sex ratio in relation to paternal phenotype, laying date and year, in the collared 459 flycatcher

\begin{tabular}{lccccc}
\hline Variable & $d f$ & $F$ & $p$ & $r$ & $95 \%$ CI \\
\hline Attack latency & $\mathbf{1 , 2 3 . 0 0}$ & $\mathbf{1 0 . 7 8}$ & $\mathbf{0 . 0 0 3}$ & $\mathbf{0 . 5 6 5}$ & $\mathbf{0 . 2 3 5 - 0 . 7 7 8}$ \\
Tarsus length & $\mathbf{1 , 9 . 1 9}$ & $\mathbf{1 1 . 2 0}$ & $\mathbf{0 . 0 0 8}$ & $\mathbf{0 . 7 4 1}$ & $\mathbf{0 . 5 0 3 - 0 . 8 7 5}$ \\
Laying date & $\mathbf{1 , 1 0 . 5 0}$ & $\mathbf{9 . 1 0}$ & $\mathbf{0 . 0 1 2}$ & $\mathbf{0 . 6 8 1}$ & $\mathbf{0 . 4 0 7 - 0 . 8 4 3}$ \\
Wing patch size & $1,6.45$ & 4.18 & 0.084 & 0.627 & $0.324-0.813$ \\
Forehead patch size & $1,15.20$ & 0.39 & 0.540 & 0.158 & $-0.236-0.508$ \\
Age & $1,8.23$ & 0.81 & 0.393 & 0.299 & $-0.091-0.610$ \\
Year & $2,6.00$ & 0.07 & 0.934 & 0.151 & $-0.243-0.502$ \\
\hline
\end{tabular}

460

461 Generalized linear mixed model with binomial error, logit link and Satterthwaite's 462 approximation of degrees of freedom. Variables retained in the final model are indicated in 463 bold. Values for non-significant variables are derived from models where these variables were 464 reintroduced to the final model one by one 